\title{
Is ginger effective for the treatment of Irritable Bowel Syndrome? A double blind randomized controlled pilot trial
}

\author{
Miranda A.L. VAN TILBURG, PhD, Olafur S. PALSSON, PsyD, Yehuda RINGEL, MD, and \\ William E WHITEHEAD, PhD \\ University of North Carolina, Department of Medicine, Division of Gastroenterology and \\ Hepatology, UNC Center for Functional GI and Motility Disorders
}

\begin{abstract}
Objectives-Ginger is one of the most commonly used herbal medicine for Irritable Bowel Syndrome (IBS) but no data exists about its effectiveness.

Design-Double blind randomized controlled trial

Setting-University of North Carolina, Chapel Hill North Carolina, USA

Intervention-Forty-five IBS patients were randomly assigned to three groups: placebo, one gram of ginger, and two grams of ginger daily for 28 days.

Main outcome measures-The IBS severity scale (IBS-SS) was administered, as well as adequate relief of symptoms scale. A responder was defined as having at least $25 \%$ reduction in IBS-SS post-treatment.

Results-There were $57.1 \%$ responders to placebo, $46.7 \%$ to one gram and $33.3 \%$ to two grams of ginger. Adequate relief was reported by $53.3 \%$ on placebo and $53.3 \%$ in both ginger groups combined. Side effects were mild and reported by $35.7 \%$ in the placebo and $16.7 \%$ in the ginger groups.
\end{abstract}

Conclusions-This double blind randomized controlled pilot study suggests ginger is well tolerated but did not perform better than placebo. Larger trials are needed before any definitive conclusions can be drawn.

\section{Keywords}

Irritable Bowel Syndrome; ginger; Randomized Controlled Trial; placebo

\section{Introduction}

Irritable Bowel Syndrome (IBS) is a common chronic condition consisting of abdominal pain with changes in bowel habits. The effectiveness of treatments for IBS are limited and

\footnotetext{
(c) 2014 Elsevier Ltd. All rights reserved.

Please send correspondence to: Miranda van Tilburg, PhD; University of North Carolina, 130 Mason Farm rd \#4106; CB 7080; Chapel Hill NC 275199-7080; Phone +1 919843 0688; Tilburg@ med.unc.edu.

Conflict of interest statement

No competing financial interests exist.

Publisher's Disclaimer: This is a PDF file of an unedited manuscript that has been accepted for publication. As a service to our customers we are providing this early version of the manuscript. The manuscript will undergo copyediting, typesetting, and review of the resulting proof before it is published in its final citable form. Please note that during the production process errors may be discovered which could affect the content, and all legal disclaimers that apply to the journal pertain.
} 
about $40 \%$ of patients use alternative medicine to treat their symptoms ${ }^{1}$. The most popular alternative medicine in a large study of 600 IBS patients was ginger ${ }^{1}$.

Ginger root is the rhizome of the perennial plant Zingiber Officinalis Roscoe. Ginger contains $1-3 \%$ of oils. Ginger dosing is often standardized according to gingerol content which is assumed to have antiemetic, analgesic, sedative, antibacterial and other physiological effects though other non-volatiles may have some of the same effects ${ }^{2-4}$. Ginger is on the American Food and Drug Administration Generally Recognized as Safe list meaning that it is considered safe and is exempted from premarket review, approval, and clinical testing before marketing (http://www.fda.gov/Food/IngredientsPackagingLabeling/ GRAS/ucm2006850.htm).

There is some evidence to suggest that ginger can affect IBS symptoms. In Micromedex (an evidence based clinical reference tool for hospitals and physicians; www.micromedex.com) ginger is classified as a broad spectrum antiemetic, and is effective in treating nausea and vomiting associated with pregnancy ${ }^{5}$ and surgery ${ }^{6}$. Ginger has also been found to influence pain and gut motility ${ }^{2}, 4$. Thus, ginger may be useful in reducing both pain and stool changes in IBS.

Given the known gastrointestinal effects of ginger, its common use among IBS patients and its wide availability and low cost, ginger should be tested as a potential treatment for IBS. The goal of this pilot study was to test the effects of ginger on IBS symptoms through a randomized placebo and dose dependent controlled trial. We chose to run a pilot study to look for signal and magnitude of clinical effect to support the rational and direct the design of a larger study

\section{Methods}

\section{Subjects}

Subjects were 45 patients age 18 and older with a physician diagnosis of Irritable Bowel Syndrome (IBS) verified by Rome III criteria. Patients were identified by sending a mass email to all students, staff, and faculty at the University of North Carolina. All participants needed to have symptoms at least once a week severe enough to interfere with daily activities and report being on a stable dose of current medications for IBS for at least 4 weeks. Subjects were excluded if they reported: (a) regular use of ginger (b) ginger allergy/ intolerance, (c) history of surgical resection of part of the gastrointestinal tract, (d) being pregnant or planning to become pregnant, or (e) use of cardiotonic or diabetic medications contra-indicated for use with ginger.

The study employed a randomized, controlled, parallel group design in which 15 subjects were randomly assigned to each of three arms: placebo, one gram ginger daily, or two grams ginger daily. Treatment duration was 28 days. Most previous trials of gastrointestinal related symptoms, such as nausea/vomiting associated with cancer or pregnancy, have used similar 1-2 grams daily doses ${ }^{5,7}$. Given that no previous studies have tested the use of ginger in IBS patients, we have no information to guide power analyses for a trial. Therefore, we chose to run an initial trial with 15 subjects in each arm to look for signal and magnitude of clinical effect to support the rational and direct the design of a larger study.

\section{Study design}

All patients completed consent, screening and baseline questionnaires online. More patients expressed interest in participation than the required 45 - only the first 45 were invited to participate. Upon randomization (by a perl-based computer program), a one month supply of ginger or placebo capsules was sent by mail. Packages included instructions on starting and 
stopping dates. Patients were contacted within 24 hours of ingesting first capsule, and biweekly thereafter to check for compliance and side effects. The study was approved by the Institutional Review Board of the University of North Carolina (approval\# 07-1035).

\section{Ginger and placebo capsules}

The ginger and placebo capsules were blister packed to ensure blinding 8 , by a compounding pharmacy. The pharmaceutical grade ginger contained $2.29 \mathrm{mg} / \mathrm{g}$ of gingerols and 6shogaols. The placebo contained brown sugar. The pharmacy coded the capsules for blinding and sent a coding key via mail at study completion.

\section{Measures}

Irritable Bowel Syndrome Severity Scale (IBS-SS)—The IBS-SS ${ }^{9}$ measures IBS severity with five items (severity and frequency of pain, abdominal distension, bowel dissatisfaction, and interference with life) rated on a 0-100 scale. A responder was defined as at least a $25 \%$ reduction in IBS-SS scores post-treatment.

Adequate Relief Rating Scale (ARRS)—At the end of treatment, patients were asked to respond to the question, "In the last week, have you had adequate relief of your abdominal pain and other symptoms of IBS (yes or no)?"10.

\section{Data analyses}

Paired t-test were run to compare IBS severity scores before and after treatment. Percentage of responders and ARRS was compared across the three treatment arms with Chi2 tests.

\section{Results}

One-hundred-eighty-one interested patients responded to study notices and completed screening. Of this group the first 45 eligible patients were invited to participate (see Figure 1 for a CONSORT diagram). No differences between the 3 treatment arms were found in gender, age and IBS-SS scores at baseline. Treatment compliance was acceptable: $97.3 \%$ in the placebo group, $98.5 \%$ in the 1 gram ginger group, and $85.2 \%$ in the 2 gram ginger group. Side effects were mild and reported by $35.7 \%$ in the placebo and $16.7 \%$ in the ginger groups. Except for two subjects who reported headaches and tiredness, all side effects were gastrointestinal symptoms including heart-burn, nausea, difficulty passing stool, more frequent stools, loose stools, bloating and hunger suppression.

IBS severity scores before and after treatment are given in Table 1. Placebo and 1 gram ginger groups saw a significant reduction in symptoms by $34.8 \%$ and $26.4 \%$ respectively. Number of treatment responders across groups was not different $(57.1 \%$ placebo, $46.7 \% 1 \mathrm{gr}$ ginger, $33.3 \% 2$ grams ginger; $p>.05$ ). Adequate relief was reported by $53.3 \%$ in the placebo group and $53.3 \%$ in both the ginger groups ( $>$ >.05).

\section{Discussion}

Ginger is one of the most commonly used herbal medicines by IBS patients ${ }^{1}$. This is the first study to date that examines the effectiveness of ginger in IBS. Since this is a pilot study, it may not be powered to find significant results. Therefore, we examined trends in the effects of ginger that would suggest ginger might be an effective treatment in a larger trial. Instead, we found a trend for IBS symptoms to improve more with placebo than ginger.

This study had several strengths including the randomized controlled design, the use of pharmaceutical grade ginger with known gingerol content, and assuring blinding of study 
participants by using blister packs. However, the study also had several limitations, including the small sample size, the short treatment duration, recruitment among university employees and students as well as the absence of blinding of investigators during the analysis phase of the study. These limit our ability to generalize and draw any definitive conclusions about the effects of ginger on IBS. Larger trials of longer duration are needed.

The placebo effect is known to be strong in studies on treatment response in IBS patients. On average a $40 \%$ placebo response has been found in IBS trials ${ }^{11}$. Our placebo response was considerably higher at $57 \%$. The placebo group also reported twice as many side effects as the ginger group, corroborating the placebo effect. The placebo effect includes a regression to the mean, natural history of the disease as well as treatment expectancies. Treatment expectancies can be raised by verbal and non-verbal cues ${ }^{12}$ of which many will be delivered within the clinic setting and direct patient-physician interactions. We minimized most of these factors by having no participants visit a clinic, no face-to-face contact with the researchers, and taking efforts to assure blinding (by using blister packs to conceal smell and providing color and texture of placebo comparable to ginger). Most other IBS treatment trials have not minimized or manipulated the placebo response ${ }^{11}$.

However, the placebo effect is influenced by many factors some of which are not always obvious. For example, patients do not have to be blinded to display a strong placebo effect if the right cues are provided. Kaptchuk and colleagues showed that an open label inactive placebo pill produced better outcomes in IBS patients compared to no treatment ${ }^{13}$. In Kaptchuk's study the placebo was introduced as powerful, having a conditioned effect on the body, and becoming stronger with a positive attitude. These instructions may have increased the likelihood of a positive response to placebo. Although we took measures to blind our participants and minimize nonspecific placebo effects within patient-clinician interactions, we may have raised treatment expectancies by informing potential subjects in the consent form that many IBS patients use ginger to treat symptoms, ginger can have effects on pain and motility, and ginger may be a potential new treatment for IBS. Thus, we may have generated a placebo response with the information we provided to the subjects. Future studies are needed to examine context and cues in treatment trials of ginger.

Previous studies have shown that ginger effectively treats gastrointestinal symptoms, has antiemetic as well as pain relieving effects, and is one of the most widely used herbal medicines by IBS patients $1,2,4-7$. These observations suggest a role of ginger in the treatment of IBS. The current study does not support this, but is in need of replication. Ginger's placebo response needs to be accounted for when designing future clinical trials. Investigators should pay attention to cues and suggestions of the efficacy of ginger in IBS.

Kaptchuk and colleagues ${ }^{13}$ suggests that recommending a placebo may be reasonable for certain disorders such as IBS, if carefully monitored by the physician. Whether or not ginger may prove to be effective for IBS in future trials, in the light of Kaptchuk and collegues' comments, clinicians may choose to be supportive of the use of ginger in patients who report adequate relief with this treatment while informing the patient about possible interactions with other medications and side effects.

There are additional issues, which will need to be addressed in future studies. Given ginger's prokinetic effect $^{2}$ and efficacy in treating nausea ${ }^{5-7}$, ginger may be more effective for certain subtypes of IBS or for those IBS patients who also complain of nausea or functional dyspepsia. This emphasizes the need to explore the mechanisms by which ginger may affect IBS symptoms - whether it is through anti-inflammatory, prokinetic, or other effects. Mechanistic studies may give insight into the group of patients most likely to benefit from treatment. Furthermore, although we used doses of ginger known to be effective for the 
treatment of nausea and vomiting, larger doses may be needed to reach efficacy in IBS. Ginger is generally safe up to 6 grams daily, which may have a much larger effect. Similarly, a different extract preparation with more concentrated gingerol content may also provide higher response rates. One caveat is that in our small study the efficacy of ginger decreased with larger doses. We observed a $26 \%$ decrease in symptoms with 1 gram versus $12 \%$ decrease in symptoms with 2 grams of ginger. Optimal ginger dosing will need to be examined for future trials.

In summary, the current study does not find evidence for the use of ginger in treating IBS but future larger trials are needed before any definitive conclusions can be drawn. The considerable placebo response to ginger in this small group is in need of further exploration and will have to be addressed in future trials of ginger.

\section{Acknowledgments}

This study was supported by R24 DK067674. The sponsor had no role in the study.

Drs van Tilburg, Palsson and Whitehead were involved in conception, design of the study, acquisition, analysis and interpretation of the data, and drafting of the manuscript Dr Ringel was involved in data acquisition and drafting of the manuscript.

\section{References}

1. van Tilburg MA, Palsson OS, Levy RL, et al. Complementary and alternative medicine use and cost in functional bowel disorders: a six month prospective study in a large HMO. BMC Complement Altern Med. 2008; 8:46. [PubMed: 18652682]

2. Ghayur MN, Gilani AH. Pharmacological basis for the medicinal use of ginger in gastrointestinal disorders. Dig Dis Sci. 2005; 50:1889-97. [PubMed: 16187193]

3. Grzanna R, Lindmark L, Frondoza CG. Ginger--an herbal medicinal product with broad antiinflammatory actions. J Med Food. 2005; 8:125-32. [PubMed: 16117603]

4. Terry R, Posadzki P, Watson LK, et al. The use of ginger (Zingiber officinale) for the treatment of pain: a systematic review of clinical trials. Pain Med. 2011; 12:1808-18. [PubMed: 22054010]

5. Borrelli F, Capasso R, Aviello G, et al. Effectiveness and safety of ginger in the treatment of pregnancy-induced nausea and vomiting. Obstet Gynecol. 2005; 105:849-56. [PubMed: 15802416]

6. Chaiyakunapruk N, Kitikannakorn N, Nathisuwan S, et al. The efficacy of ginger for the prevention of postoperative nausea and vomiting: a meta-analysis. Am J Obstet Gynecol. 2006; 194:95-9. [PubMed: 16389016]

7. Haniadka R, Rajeev AG, Palatty PL, et al. Zingiber officinale (ginger) as an anti-emetic in cancer chemotherapy: a review. J Altern Complement Med. 2012; 18:440-4. [PubMed: 22540971]

8. van Tilburg MA. Efficacious blinding of ginger for randomized controlled trials. Alternative Medicine Studies. 2012; 2:1-2.

9. Francis CY, Morris J, Whorwell PJ. The irritable bowel severity scoring system: a simple method of monitoring irritable bowel syndrome and its progress. Alimentary Pharmacology \& Therapeutics. 1997; 11:395-402. [PubMed: 9146781]

10. Drossman, DA.; Corazziari, E.; Delvaux, M., et al. Rome III: The Functional Gastrointestinal Disorders. McLean, Virginia: Degnon Associates; 2006.

11. Patel SM, Stason WB, Legedza A, et al. The placebo effect in irritable bowel syndrome trials: a meta-analysis. Neurogastroenterol Motil. 2005; 17:332-40. [PubMed: 15916620]

12. Colloca L, Klinger R, Flor H, et al. Placebo analgesia: psychological and neurobiological mechanisms. Pain. 2013; 154:511-4. [PubMed: 23473783]

13. Kaptchuk TJ, Friedlander E, Kelley JM, et al. Placebos without deception: a randomized controlled trial in irritable bowel syndrome. PLoS One. 2010; 5:e15591. [PubMed: 21203519] 


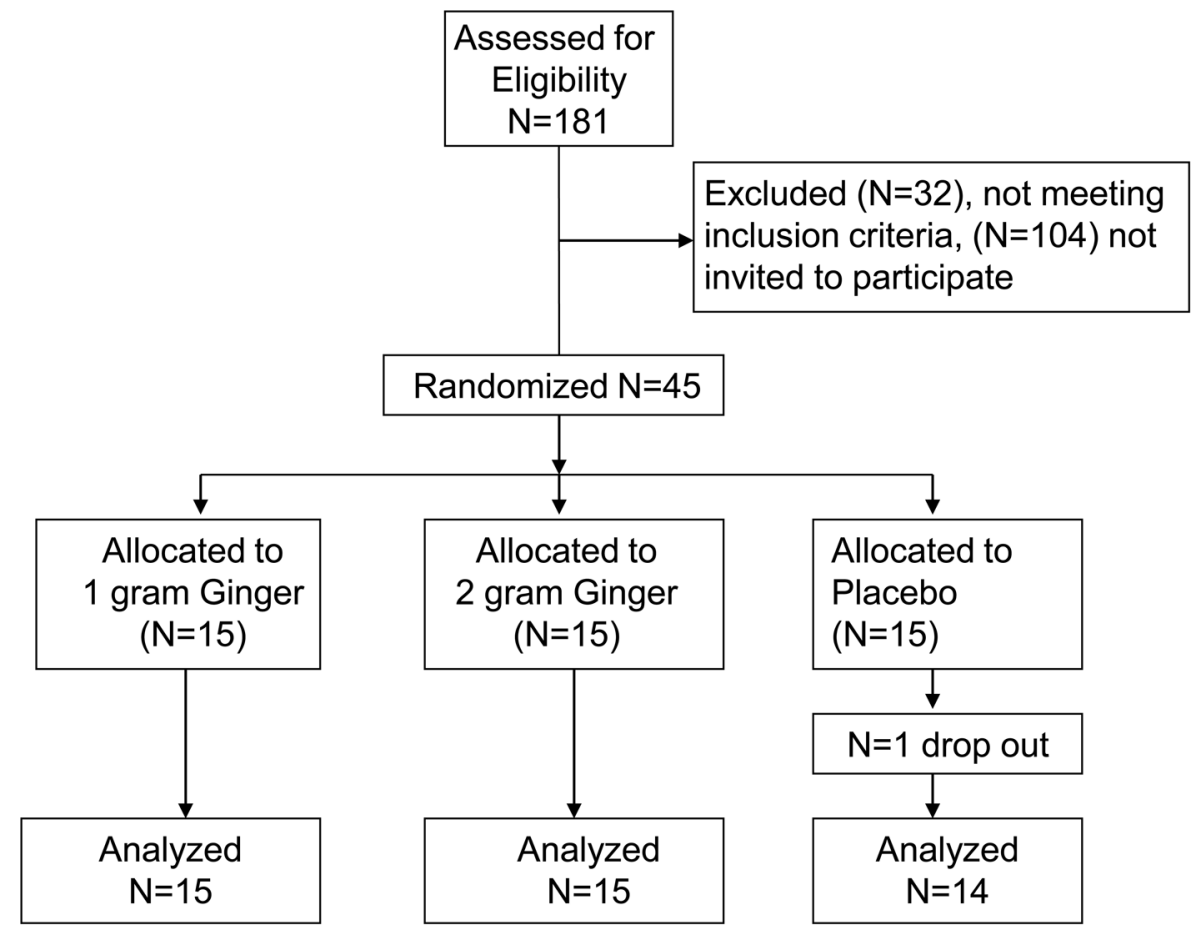

Figure 1.

Consort flow diagram. 
Table 1

IBS severity scores before and after treatment

\begin{tabular}{|l|c|c|c|}
\hline & $\begin{array}{c}\text { Pre-treatment } \\
\text { Mean }(\text { SD) }\end{array}$ & $\begin{array}{c}\text { Post-treatment } \\
\text { Mean }(\text { SD })\end{array}$ & $\mathbf{p}$ \\
\hline Placebo & $253.2(65.9)$ & $165.0(49.3)$ & .001 \\
\hline 1 gram ginger & $260.0(65.5)$ & $191.3(95.8)$ & .007 \\
\hline 2 grams ginger & $222.7(53.3)$ & $198.9(88.9)$ & .233 \\
\hline
\end{tabular}

